\title{
Marka Kişiliklerinin Instagram Aracılığıyla Sunumu: İçecek Markaları Üzerine Analiz*
}

Hakan KÜçüKSARAÇ, Kocaeli Üniversitesi Gazanfer Bilge Meslek Yüksekokulu, Öğr. Gör. Dr., hakan.kucuksarac@kocaeli.edu.tr, ORCID:0000-0002-3189-3644

ÖZ

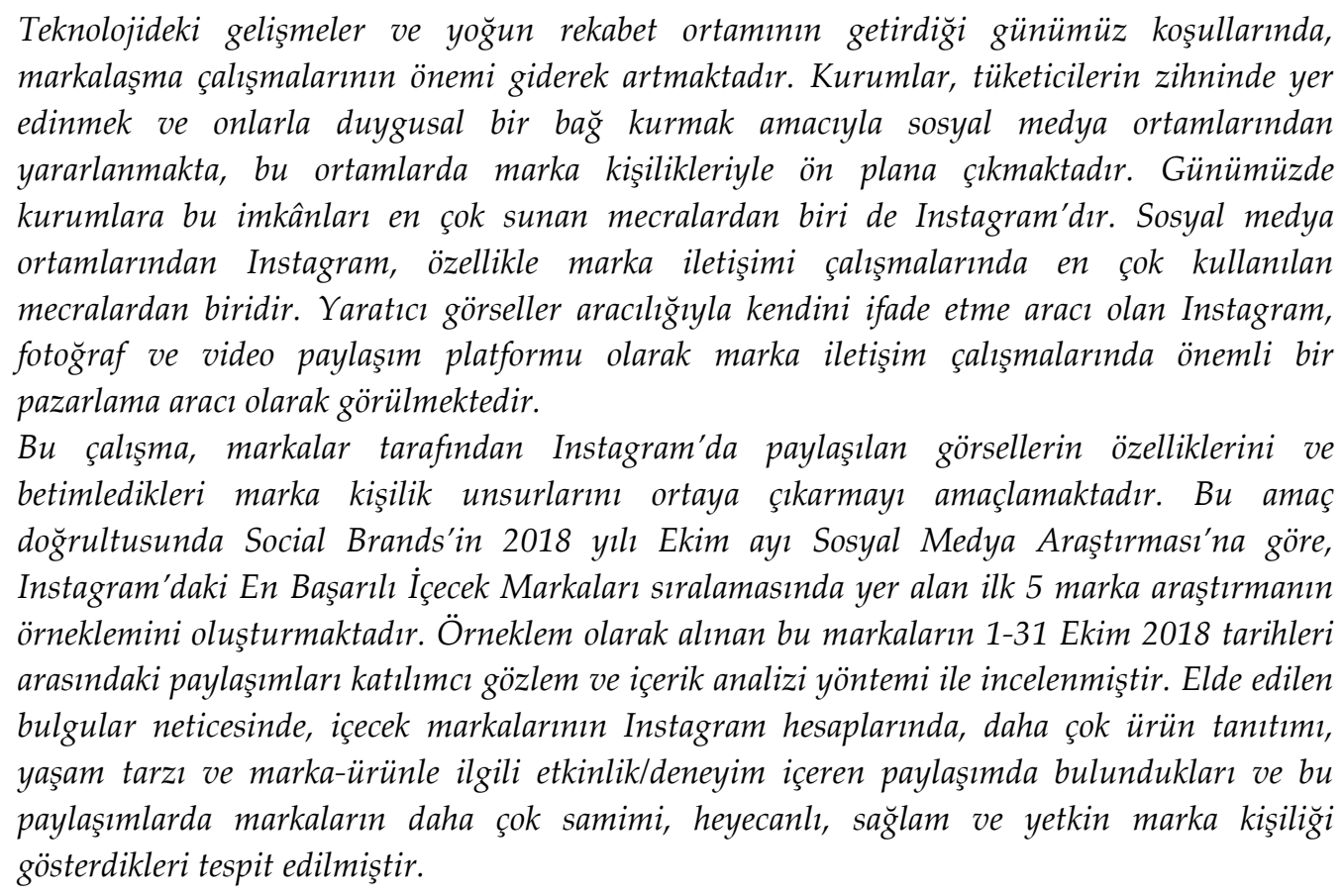

Anahtar Kelimeler: Marka iletişimi, Pazarlama iletişsimi, Instagram, Marka Kişiliği, İ̧̧ecek Markaları

\section{Presentation of Brand Personality Through Instagram: Analysis on Beverage Brands}

\begin{abstract}
In today's conditions brought by the developments in technology and the intense competition environment, the importance of branding is increasing. In order to gain a place in the minds of consumers and to establish an emotional connection with them, institutions utilize social media environments and emphasize brand personalities in these environments. Today, Instagram is one of the most popular media offering these opportunities to institutions.
\end{abstract}

\footnotetext{
* Bu makale 14-16 Aralık 2018 tarihleri arasında İstanbul'da düzenlenen Bilişim ve İletişim Teknolojileri Kongresi'nde sözlü sunumu gerçekleștirilen "Marka Kişiliklerinin Instagram Aracıllğıyla Sunumu: İçecek Markaları Üzerine Analiz" başlıklı bildirinin genişletilmiş halidir.
} 
Instagram from social media environments is one of the most widely used media especially in Brand Communication Studies. Instagram, a self-expression tool through creative visuals, is seen as an important marketing tool in brand communication studies as a photo and video sharing platform.

This study aims to reveal the characteristics of images shared by brands in Instagram and the characteristics of brand personality that they describe. For this purpose, according to Social Brands Social Media Research in October 2018, Instagram's top 5 brands in the ranking of the most successful beverage brands constitute the sample of the research. The share of these samples was examined by the participatory observation and content analysis method between October 1-31, 2018. As a result of the findings, it has been determined that beverage brands share more product promotion, lifestyle and brand-related events/experiences in Instagram accounts, and in these shares brands show more sincerity, excitement, ruggedness and competence brand personality.

Keywords: Brand Communication, Marketing Communication, Instagram, Brand Personality, Beverage Brands

\section{GİRIŞ}

Yeni iletişim teknolojilerinin gelişmesi ve yaygınlık kazanması, birçok alanda olduğu gibi pazarlama anlayışında da değişime yol açmıştır. Bu değişim, yoğun rekabet ortamının getirdiği koşullar karşısında hayatta kalmak isteyen markalar için müşteri bağlılığı, marka bilinirliği ve marka sadakati gibi noktalarda tüketicileri ile sürekli etkileşim halinde bulunabilecekleri yeni mecraların keşfi ve kullanımını gerektirmiştir. Bu yeni mecralardan biri de Instagram'dir.

Sosyal medya ortamlarından biri olan Instagram, yaratıcı görseller kullanarak kendini ifade etme, iletişim kurma ve etkileşim sağlamanın en popüler aracıdır. Fotoğraf ve video paylaşmaya yarayan bu uygulama ile kullanıcılar, kişisel hikayeleri ve ilgi alanlarını çektikleri fotoğraflar aracılığıyla paylaşarak, kendilerini istedikleri şekilde ortaya koyma özgürlüğüne sahiptir (Ginsberg, 2015: 78-79). Ting vd. (2015: 18) göre Instagram'ın bu özgürlüğü, fiziksel ve dijital alanları birbirine bağlayarak çevrimiçi var olmayı ve çevrimiçi kimliği geliştirmekte, sadece kişisel amaçlı olarak değil, aynı zamanda iş amaçlı olarak da kullanılmasını sağlamaktadır.

Instagramın diğer sosyal medya hesaplarıyla birlikte yaratıcı bir şekilde kullanılması, tüketicileri etkileme gücü ve markalara yönelik ilgi yaratma potansiyeli önemli bir pazarlama aracı olarak görülmektedir. Markalar pazarlama çabaları kapsamında, Instagram'da paylaştıkları görsellerle ürün ya da hizmetleriyle ilgili tanıtımlarının dışında tüketiciyi eğlendirmekte, onları kendi hikayelerinin içine çekerek duygusal bir bağ kurmaktadır. Böylece markalar tüketicinin zihninde "insan" olarak konumlanıp kişiliklerini vurgulamakta, tüketiciler ile daha gerçek, amacına uygun ve anlamlı bir ilişki kurmaktadır (Kale, 2016: 122-123). 
Instagram'ın marka kişiliklerini destekleyen yapısı, Bui (2014)'nin çalışmasında da vurgulanmaktadır. Bui, Instagram'ın mobil gıda satıcılarına nasıl faydalı olabileceğini araştıran çalışmasında, kullanıcıların etkili bir fotoğrafı ve markalarla olan ilişkilerini tanımlama biçimlerini incelemiştir. Buna göre markaların sadece yemek fotoğrafları paylaşmadığı, sosyal içerikli fotoğraflar da paylaştığını, böylece fotoğraf içeriğinin, ürünlerin ötesine geçerek tüketicilerle etkileşim ve bağlantı kurduğunu belirtmektedir. Bui'nin bu çalışması, Instagram'da güçlü markalar oluşturmak için, farklı fotoğraf içeriği yayınlanması gerektiğine vurgu yaparak, bu tür içeriğin markaların çok boyutlu doğasını vurguladığını, dolayısıyla bunun da marka kişiliklerine işaret ettiğini göstermektedir (Aaker, 1997: 347).

Marka kişiliği, insana ait olan karakter özelliklerinin markalarla ilişkilendirilmesidir. Diğer bir ifadeyle markaya sembolik anlamlar yükleyerek tüketicinin zihninde, markanın bir kişi gibi algılanmasını ifade etmektedir. Bu bağlamda tüketiciler markaları ürün olarak değil, sevecen, hareketli, kışkırtıcı, zarif gibi insana ait kişilik özellikleriyle algılamaktadır (Yücel \& Halifeoğlu, 2017).

Marka kişiliği ile ilgili alanyazında yapılan çalışmaların, marka özellikleri ve kişilik özellikleri olarak temellendiği görülmektedir (Milas \& Mlacic, 2007: 620; Yakın \& Ay, 2012; Meer, 2010; Yılmaz, 2007). Aaker marka kişiliği tanımı kapsamında, kişilik özelliklerini marka ile ilişkilendirerek, psikoloji alanında genel kabul görmüş kişilik ölçeklerinin bu konudaki ölçek geliştirme çalışmalarında kullanılmasını sağlamıştır (Sweney\&Brandon, 2006: 640; Milas \& Mlacic, 2007: 620). Bu kapsamda, psikoloji alanında kişilik sınıflandırmasında temel bir çerçeve oluşturan beş faktörlü kişilik modeli (Goldberg, 1993: 27), pazarlama alanında Aaker (1997) tarafından geliştirilen marka kişiliği ölçeğine temel oluşturmuştur. Beş faktörlü kişilik sınıflaması dâhilinde bireyin kişiliğinden yola çıkan Aaker, marka kişiliğini niteleyen özelliklerin samimiyet, heyecan, yetkinlik, seçkinlik ve sağlamlık olmak üzere beş boyutta ele alınabileceğini belirtmektedir (Dölarslan, 2012: 3).

Plummer ise "How Personality Makes a Difference" (2000) adlı çalışmasında, markaların tüketici zihninde oluşan algılarının kendine özgü bir kişilik barındırdığını belirtmiştir. Buna göre; markaların da insanlar gibi kişilik özellikleriyle değerlendirilebileceği ve marka kişiliklerinin tüketicilerle etkileşim noktasında faydalanılan bir unsur olduğu ifade edilmiştir.

Sonuç olarak marka kişiliği, tüketicilerin marka hakkındaki algılamaları ve tutumlarına ilişkin anlayışlarını güçlendirerek farklılaşmış bir marka kimliğinin oluşmasına katkıda bulunmakta, markayla ilgili iletişim çalışmalarını desteklemekte, markaya yönelik olumlu tutum ve davranış geliştirerek markaya değer katmaktadır (Torlak ve Özçelik, 2011: 363)

\section{Amaç}

$\mathrm{Bu}$ çalışma, içecek markaları tarafından pazarlama ve iletişim taktiği olarak Instagram'da paylaşılan görsellerin özelliklerini ve betimledikleri marka kişilik unsurlarını ortaya çıkarmayı amaçlamaktadır. Bu amaç doğrultusunda araştırmada 2 temel soruya yanıt aranmaktadır: 
1. Markalar tarafından pazarlama ve iletişim taktiği olarak Instagram'da kullanılan görsellerin özellikleri nelerdir?

2. Bu görseller nasıl bir marka kişiliği sergilemektedir?

\section{Yöntem}

Marka iletişimi açısından pazarlama ve iletişim taktiği olarak Instagram'da paylaşılan görsellerin özellikleri ve betimledikleri marka kişilik unsurlarını içecek markaları üzerinden ortaya çıkarmayı amaçlayan bu çalışmada tanımlayıcı/betimleyici araştırma tasarımı temel alınmıştır. Böylece, içecek markalarının Instagram hesaplarındaki paylaşımlarla ilgili mevcut durumlarını ortaya çıkarmak amaçlanmıştır.

$\mathrm{Bu}$ amaç doğrultusunda Social Brands'in 2018 yılı Ekim ayı Sosyal Medya Araştırması'na göre, Instagram'daki En Başarılı İçecek Markaları sıralamasında yer alan ilk 5 marka araştırmanın örneklemini oluşturmaktadır. Örneklem olarak alınan bu markaların 1-31 Ekim 2018 tarihleri arasındaki paylaşımları Ginsberg (2015) ve Aeker (1997)'ın çalışmalarından yararlanılarak katılımcı gözlem ve içerik analizi yöntemleriyle analiz edilmiştir.

Katılımcı gözlem, yapılandırılmamış alan çalışmasının bir parçası olarak davranışın gerçekleştiği doğal ortamlarda yapılan ve araştırmacının açık veya gizli kimliğiyle ortama katıldığı araştırma türüdür (Yıldırım \& Şimşek, 2006: 171). Çevrimiçi ortamlarda katılımcı gözlem ise, araştırmacının "pusucu (lurcher)" konumunda olduğu, çevrimiçi ortamlardaki faaliyetlere aktif olarak katılmadan bulunduğu araştırma türünü ifade etmektedir. Buna göre, pusucu sadece ortamı gözlemlemekte, yorum veya paylaşımda bulunmamaktadır (Alyanak, 2014: 140).

İçerik analizi ise, iletişim içeriğinin, genellikle önceden belirlenmiş sınıflamalar (kategoriler) çerçevesinde sistematik olarak gerçekleştirilmesini sağlayan bir araştırma tekniğidir (Geray, 2004). İçerik analizinde temelde yapılan işlem, birbirine benzeyen verileri belirli kavramlar ve temalar çerçevesinde bir araya getirmektir.

Araştırma kapsamında, örneklem olarak belirlenen Instagram sayfalarına üye/takipçi olunarak 1-31 Ekim 2018 tarihleri arasında katılımcı gözlemde bulunulmuş ve bu sayfalara ait içerikler web arayüzü kullanılarak pdf formatında kayıt edilmiştir. Ginsberg (2015)'in 11 kategoride topladı̆̆ 1 temalardan yararlanılarak, incelenen markaların belirtilen tarihler arasında paylaştıkları görsellerin özelliklerine göre temalar yeniden oluşturulmuştur. Buna göre Ek1'de de görüldüğü üzere 14 tema belirlenmiş, kodlamalar ve analizler bu temalara göre gerçekleştirilmiştir.

\section{Araştırma Bulguları}

Marka iletişimi açısından pazarlama ve iletişim taktiği olarak Instagram'da paylaşılan görsellerin özellikleri ve betimledikleri marka kişilik unsurlarını içecek markaları üzerinden incelemeyi temel alan araştırma kapsamında örneklem olarak seçilen markaların Instagram hesapları ve bunlara ait analizler aşağıdaki gibidir. 
Tablo 1: Profil Analizi

\begin{tabular}{|c|l|c|c|c|}
\hline No & Marka & Takipçi Sayısı & Etkileşim Sayısı & İleti Sayısı \\
\hline 1 & Red Bull Türkiye & 101.173 & 72.923 & 36 \\
\hline 2 & DİMES Türkiye & 23.569 & 15.332 & 18 \\
\hline 3 & Juico & 38.564 & 9.983 & 15 \\
\hline 4 & Herby Tea & 5.523 & 17.249 & 17 \\
\hline 5 & Mahmood Coffee & 11.090 & 9.794 & 15 \\
\hline
\end{tabular}

Araştırma kapsamına dahil edilen markalara ait takipçi sayısı, etkileşim sayısı ve ileti sayısı Tablo 1'de gösterilmektedir. Buna göre, Red Bull Türkiye 101.173 takipçi sayısı ve 72.923 etkileşim sayısı ile birinci sırada yer almaktadır. Red Bull Türkiye'yi Dimes Türkiye, Juico, Herby Tea ve Mahmood Coffee takip etmektedir. Bu markaların takipçi sayılarının 5.523 ile 38.564 arasında, etkileşim sayılarının ise 9.794 ile 17.249 arasında, ileti sayılarının ise 15 ile 36 arasında olduğu görülmektedir.

Tablo 2: İleti Türleri

\begin{tabular}{|c|c|c|c|c|c|c|c|c|c|c|c|}
\hline \multirow[t]{2}{*}{ No } & \multirow[t]{2}{*}{ İleti Türleri } & \multicolumn{2}{|c|}{$\begin{array}{l}\text { RedBull } \\
\text { Türkiye }\end{array}$} & \multicolumn{2}{|c|}{$\begin{array}{c}\text { DİMES } \\
\text { Türkiye }\end{array}$} & \multicolumn{2}{|c|}{ Juico } & \multicolumn{2}{|c|}{ HerbyTea } & \multicolumn{2}{|c|}{$\begin{array}{c}\text { Mahmood } \\
\text { Coffee }\end{array}$} \\
\hline & & $\mathbf{n}$ & $\%$ & $\mathbf{n}$ & $\%$ & $\mathbf{n}$ & $\%$ & $\mathbf{n}$ & $\%$ & $\mathbf{n}$ & $\%$ \\
\hline 1 & Fotoğraf / Grafik & 4 & 11 & 17 & 94 & 14 & 94 & 17 & 100 & 8 & 53 \\
\hline 2 & Video / Animasyon & 32 & 89 & 1 & 6 & 1 & 6 & - & - & 7 & 47 \\
\hline & TOPLAM & \multicolumn{2}{|c|}{36} & \multicolumn{2}{|c|}{18} & \multicolumn{2}{|c|}{15} & \multicolumn{2}{|c|}{17} & \multicolumn{2}{|c|}{15} \\
\hline
\end{tabular}

Tablo2'ye göre, markaların Instagram hesaplarında paylaştıkları ileti türlerine bakıldığında, Red Bull Türkiye'nin ağırlıklı olarak (\%89) video/animasyon türünde ileti paylaştı̆̆ı, diğer markaların ise daha çok fotoğraf/grafik türünde ileti paylaştıkları görülmektedir. Bu durum Red Bull'un extrem sporlarla olan yakın ilişkisi ve marka kişilik özelliklerinden kaynaklanmakla birlikte, hedef kitlesinde daha fazla etki bırakmak ve görsel deneyimi tam olarak aktarabilmek amacıyla video türünde iletilere ağırlık verdiği söylenebilmektedir.

\section{Tablo 3: Görsel İçerik Analizi-Tematik Analiz}

\begin{tabular}{|c|c|c|c|c|c|c|c|c|c|c|c|}
\hline \multirow[t]{2}{*}{ No } & \multirow[t]{2}{*}{ Görsel İçerik } & \multicolumn{2}{|c|}{$\begin{array}{l}\text { Red Bull } \\
\text { Türkiye }\end{array}$} & \multicolumn{2}{|c|}{$\begin{array}{l}\text { DİMES } \\
\text { Türkiye }\end{array}$} & \multicolumn{2}{|c|}{ Juico } & \multicolumn{2}{|c|}{ Herby Tea } & \multicolumn{2}{|c|}{$\begin{array}{l}\text { Mahmood } \\
\text { Coffee }\end{array}$} \\
\hline & & $\mathbf{n}$ & $\%$ & $\mathbf{n}$ & $\%$ & $\mathbf{n}$ & $\%$ & $\mathbf{n}$ & $\%$ & $\mathbf{n}$ & $\%$ \\
\hline 1 & Ürün & - & - & - & - & 8 & $\% 54$ & 8 & $\% 47$ & 3 & $\% 21$ \\
\hline 2 & Ürün kampanya & - & - & - & - & 2 & $\% 13$ & 1 & $\% 6$ & 2 & $\% 13$ \\
\hline 3 & Kiși/kișiler ve ürün & 1 & $\% 3$ & 7 & $\% 38$ & 1 & $\% 7$ & - & - & - & - \\
\hline 4 & $\begin{array}{l}\text { Mizah/eğlence ve } \\
\text { ürün }\end{array}$ & 1 & $\% 3$ & - & - & - & - & - & - & 2 & $\% 13$ \\
\hline 5 & $\begin{array}{l}\text { Marka bağlantılı } \\
\text { organizasyon }\end{array}$ & 9 & $\% 25$ & - & - & - & - & - & - & - & - \\
\hline 6 & $\begin{array}{l}\text { Marka /ürün içeren } \\
\text { etkinlik/ deneyim }\end{array}$ & 13 & $\% 36$ & - & - & - & - & - & - & - & - \\
\hline
\end{tabular}


AJIT-e: Online Academic Journal of Information Technology

2018- Informatics and Communication Technologies Special Issue/iletişim ve Bilişim Teknolojileri

Özel Sayı -Cilt/Vol: 9-Sayı/Num: 35

DOI: 10.5824/1309-1581.2018.5.004.x

\begin{tabular}{|c|c|c|c|c|c|c|c|c|c|c|c|}
\hline \multirow[t]{2}{*}{ No } & \multirow[t]{2}{*}{ Görsel İçerik } & \multicolumn{2}{|c|}{$\begin{array}{l}\text { Red Bull } \\
\text { Türkiye }\end{array}$} & \multicolumn{2}{|c|}{$\begin{array}{c}\text { DİMES } \\
\text { Türkiye }\end{array}$} & \multicolumn{2}{|c|}{ Juico } & \multicolumn{2}{|c|}{ Herby Tea } & \multicolumn{2}{|c|}{$\begin{array}{c}\text { Mahmood } \\
\text { Coffee }\end{array}$} \\
\hline & & $\mathbf{n}$ & $\%$ & $\mathbf{n}$ & $\%$ & $\mathbf{n}$ & $\%$ & $\mathbf{n}$ & $\%$ & $\mathbf{n}$ & $\%$ \\
\hline 7 & $\begin{array}{l}\text { Marka ve ürünü } \\
\text { içermeyen } \\
\text { kampanya desteği }\end{array}$ & 1 & $\% 3$ & - & - & - & - & - & - & - & - \\
\hline 8 & $\begin{array}{l}\text { Marka ve ürünü } \\
\text { içeren kampanya } \\
\text { desteği }\end{array}$ & - & - & - & - & - & - & 1 & $\% 6$ & - & - \\
\hline 9 & $\begin{array}{l}\text { Marka bağlantısız } \\
\text { deneyim/olay }\end{array}$ & 8 & $\% 22$ & - & - & - & - & - & - & - & - \\
\hline 10 & Kutlama/Anma & 3 & $\% 8$ & 1 & $\% 6$ & - & - & 1 & $\% 6$ & 4 & $\% 27$ \\
\hline 11 & $\begin{array}{l}\text { Tarifler/Ürün } \\
\text { kullanımları }\end{array}$ & - & - & 2 & $\% 11$ & 2 & $\% 13$ & 2 & $\% 12$ & 2 & $\% 13$ \\
\hline 12 & $\begin{array}{l}\text { Yaşam Biçimi - } \\
\text { ürünü destekleyen } \\
\text { içerik }\end{array}$ & - & - & 1 & $\% 6$ & 2 & $\% 13$ & 4 & $\% 23$ & 2 & $\% 13$ \\
\hline 13 & $\begin{array}{l}\text { Yaşam Biçimi - bir } \\
\text { ürünü } \\
\text { desteklemeyen } \\
\text { ancak marka ile } \\
\text { bağlantılı içerik }\end{array}$ & - & - & 2 & $\% 11$ & - & - & - & - & - & - \\
\hline 14 & $\begin{array}{l}\text { Yaşam Biçimi - bir } \\
\text { ürünü desteklemeyen } \\
\text { ve marka ile bağlantıll } \\
\text { olmayan içerik }\end{array}$ & - & - & 5 & $\% 28$ & - & - & - & - & - & - \\
\hline & TOPLAM & 36 & 100 & 18 & 100 & 15 & 100 & 17 & 100 & 15 & 100 \\
\hline
\end{tabular}

Markaların pazarlama ve iletişim taktiği olarak Instagram hesaplarında paylaştıkları görsellerin içerik özellikleri, Tablo3'de görüldügüü üzere 14 tema üzerinden analiz edilmiştir:

Social Brands'in 2018 yılı Ekim ayı Sosyal Medya Araştırması'na göre, içecek markaları arasında Instagram'da birinci sırada yer alan Red Bull Türkiye, özellikli bir hedef kitleye hitap etmesine rağmen herkes tarafından bilinen enerji içeceği markasıdır. Red Bull Türkiye'nin, analiz kapsamında 36 görsel iletisine erişilmiştir. Bu içeriklerin \%89'u video türünde olmakla birlikte, içerik özellikleri bakımından \%36 "marka/ürün içeren etkinlik/deneyim", \%25 "marka bağlantılı organizasyon", \%22 "marka bağlantısız deneyim/olay" olduğu görülmektedir. Sonuç olarak Red Bull Türkiye'nin Instagram hesabında paylaştığı görsellerin çoğunun ürün tanıtımı, kampanya ya da yaşam biçiminden ziyade etkinlik, deneyim ve organizasyona odaklanması, hedef kitleyle kurduğu yüzyüze iletişim ve etkileşimi göstererek, markanın sosyal ve kültürel yönlerini vurgulamaktadır.

Dimes Türkiye, her yaştan geniş bir hedef kitleye hitap eden ve herkes tarafından bilinen meyve suyu markasıdır. Analiz kapsamında Dimes Türkiye'nin 18 görsel iletisine erişilmiştir. Bunların \%94'ü fotoğraf/grafik olmakla birlikte, içerik özellikleri bakımından \%38'i "kişi/kişiler ve ürün", \%28'i "yaşam biçimi-bir ürünü desteklemeyen ve marka ile bağlantılı olmayan içerik", \%11'i "tarifler/ürün kullanımları" ile "yaşam biçimi-bir ürünü desteklemeyen ancak marka ile bağlantılı içerik" olduğu görülmektedir. Bu bağlamda Dimes 
Türkiye'nin Instagram'daki paylaşımlarında ürün/ürünlerini gerek kişi/kişilerle gerekse de tarifler şeklinde ön plana çıkardığı, bunun yanı sıra ürün veya marka ile bağlantılı ya da bağlantısız yaşam biçimi iletilerinde bulunduğu görülmektedir.

Juico, soğuk sıkım meyve-sebze suyu ve sağlıklı beslenme markası olarak, özellikli bir hedef kitleye hitap etmektedir. Analiz kapsamında Juico'nun 15 görsel iletisine erişilmiş olup, bunların \%94'ü fotoğraf/grafiktir. Juico'nun Instagram sayfasında paylaştığ görsellerin içerik özelliklerine bakıldığında; bunların \%54'ünün "ürün”, \%13'nün "ürün kampanya”, "tarifler/ürün kullanımları" ile "yaşam biçimi-ürünü destekleyen içerik" olduğu görülmektedir. Bu bağlamda Juico'nun Instagram'daki paylaşımlarında gerek kampanya, gerekse tarifler ve yaşam biçimi önerileriyle ürünlerini ön plana çıkardığı tespit edilmiştir.

Herby Tea, fonksiyonel bitki çayları markası olarak bilinçli/seçici bir hedef kitleye hitap etmektedir. Analiz kapsamında Herby Tea'nin 17 görsel iletisine erişilmiş olup, bunların \%100'ü fotoğraf/grafiktir. Herby Tea'nin Instagram sayfasında paylaştı̆̆ 1 görsellerin içerik özelliklerine bakıldığında; \%47'sinin "ürün", \%23'ünün "yaşam biçimi-ürünü destekleyen içerik", \%12'sinin ise "tarifler/ürün kullanımları" olduğu görülmektedir. Bu bağlamda Herby Tea'nin de gerek tarifler gerekse yaşam biçimi önerileriyle ürünlerini ön plana çıkardığı söylenebilmektedir.

Kahve markası olan Mahmood Coffee ise, kahve tüketicisi genel bir hedef kitleye hitap etmektedir. Analiz kapsamında Mahmood Coffee'nin 15 görsel iletisine erişilmiş olup, bunların \%53'ü fotoğraf/grafiktir. Mahmood Coffee'nin Instagram sayfasında paylaştığ görsellerin içerik özelliklerine bakıldığında; \%27'sinin "kutlama/anma", \%21'inin "ürün" olduğu görülmektedir. Bu bağlamda Mahmood Coffee'nin "kutlama/anma" ile ilgili görseller yayınlayarak yerel/ulusal tüketici kitlesine hitap ettiği, aynı zamanda ürün tanıtımını da ön planda tuttuğu söylenebilmektedir.

Tablo 4: Marka Kişiliği Boyutları

\begin{tabular}{|c|l|c|c|c|c|c|c|c|c|c|c|}
\hline \multirow{2}{*}{ No } & \multirow{2}{*}{$\begin{array}{l}\text { Marka } \\
\text { Kişiliği }\end{array}$} & \multicolumn{2}{|c|}{$\begin{array}{l}\text { RedBull } \\
\text { Türkiye }\end{array}$} & \multicolumn{2}{|c|}{$\begin{array}{c}\text { DiMES } \\
\text { Türkiye }\end{array}$} & \multicolumn{2}{|c|}{ Juico } & \multicolumn{2}{|c|}{ HerbyTea } & \multicolumn{2}{c|}{$\begin{array}{c}\text { Mahmood } \\
\text { Coffee }\end{array}$} \\
\cline { 3 - 13 } & Boyutları & $\mathbf{n}$ & $\mathbf{\%}$ & $\mathbf{n}$ & $\mathbf{\%}$ & $\mathbf{n}$ & $\mathbf{\%}$ & $\mathbf{n}$ & $\mathbf{\%}$ & $\mathbf{n}$ & $\mathbf{\%}$ \\
\hline $\mathbf{1}$ & Samimi & 7 & 9 & 16 & 84 & 10 & 50 & 9 & 50 & 11 & 69 \\
\hline $\mathbf{2}$ & Heyecanlı & 20 & 27 & 2 & 11 & 3 & 15 & 5 & 28 & 2 & 12,50 \\
\hline $\mathbf{3}$ & Yetkin & 16 & 21 & - & - & 2 & 10 & 1 & 5,5 & 2 & 12,50 \\
\hline $\mathbf{4}$ & Seçkinlik & 6 & 8 & 1 & 5 & 4 & 20 & 2 & 11 & - & - \\
\hline $\mathbf{5}$ & Sağlam & 26 & 35 & - & - & 1 & 5 & 1 & 5,5 & 1 & 6 \\
\hline & TOPLAM & $\mathbf{7 5}$ & $\mathbf{1 0 0}$ & $\mathbf{1 9}$ & $\mathbf{1 0 0}$ & $\mathbf{2 0}$ & $\mathbf{1 0 0}$ & $\mathbf{1 8}$ & $\mathbf{1 0 0}$ & $\mathbf{1 6}$ & $\mathbf{1 0 0}$ \\
\hline
\end{tabular}

Markaların pazarlama ve iletişim taktiği olarak, Instagram'da yayınladıkları görsellerin ne tür bir marka kişiliği profili ortaya koyduğunu belirleyebilmek için Aaker'in (1997) beş boyutlu marka kişiliği ölçeğinden yararlanılmış: samimiyet, heyecan, yetkinlik, seçkinlik ve sağlamlık boyutları üzerinden markaların kişilik sunumları değerlendirilmiştir. Tablo4'de de görüldüğü üzere, yapılan değerlendirmede bazı görsel içeriklerin birden fazla kişilik 
boyutuyla bağlantılı olduğu bulgulanmış, bu içerikler birden fazla kişilik boyutuyla kodlanmıştır. Tablo 4'e göre, marka bazlı kişilik boyutu analizleri aşağıdaki gibidir:

\section{Red Bull Türkiye}

Red Bull markası, incelenen markalar arasında, Instagram paylaşımlarında en çok video kullanan marka olarak öne çıkmaktadır. Özellikle marka bağlantılı organizasyonların profesyonel görüntü çekimleri sayesinde takipçilere etkileyici içerikler sunulmaktadır. Marka bağlantılı açıkhava etkinlikleri, sıra dışı meydan okumalar ve ilgili alanlarda kendini kanıtlamış profesyonellerin yer aldığı görsel sunumlar, markanın 'sağlam', 'heyecanlı' ve 'yetkin' kişilik boyutlarını ön plana çıkarmaktadır.

\section{Görsel 1: Red Bull Türkiye Marka Kişiliği Paylaşım Örnekleri}
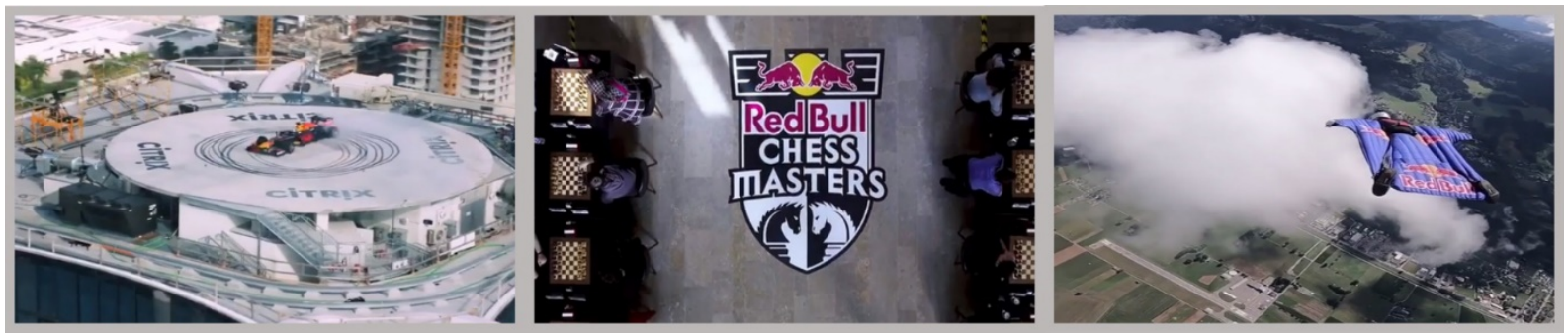

\section{DİMES Türkiye}

Dimes markası, incelenen markalar arasında, 'samimi' marka kişiliğine en fazla ağırlık veren marka olarak öne çıkmaktadır. Günlük hayattan sahneler içerisine yerleştirilmiş ürün sunumları, neşe ve umut kavramlarını ön plana çıkaran sloganlar ve ürün görseline enerji ve hareket katan kişi kullanımları ile 'samimi' marka kişilik özelliği sergilediği görülmektedir.

\section{Görsel 2: DİMES Türkiye Marka Kişiliği Paylaşım Örnekleri}

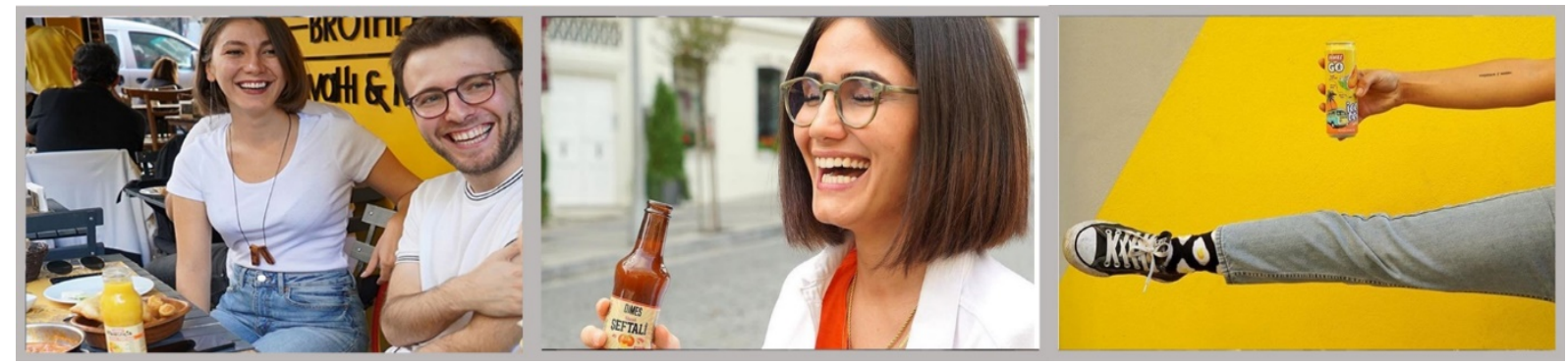

Juico

Juico markası, belirli bir kitleye ve yaşam tarzına özel ürün sınıflandırma ve sunumlarıyla 'seçkin', ürünlerin gündelik hayat ve sağlık temalı slogan ya da söylemlerle birlikte sunulmasıyla 'samimi' marka kişiliği özellikleri sergilemektedir. 
Görsel 3: Juico Marka Kişiliği Paylaşım Örnekleri
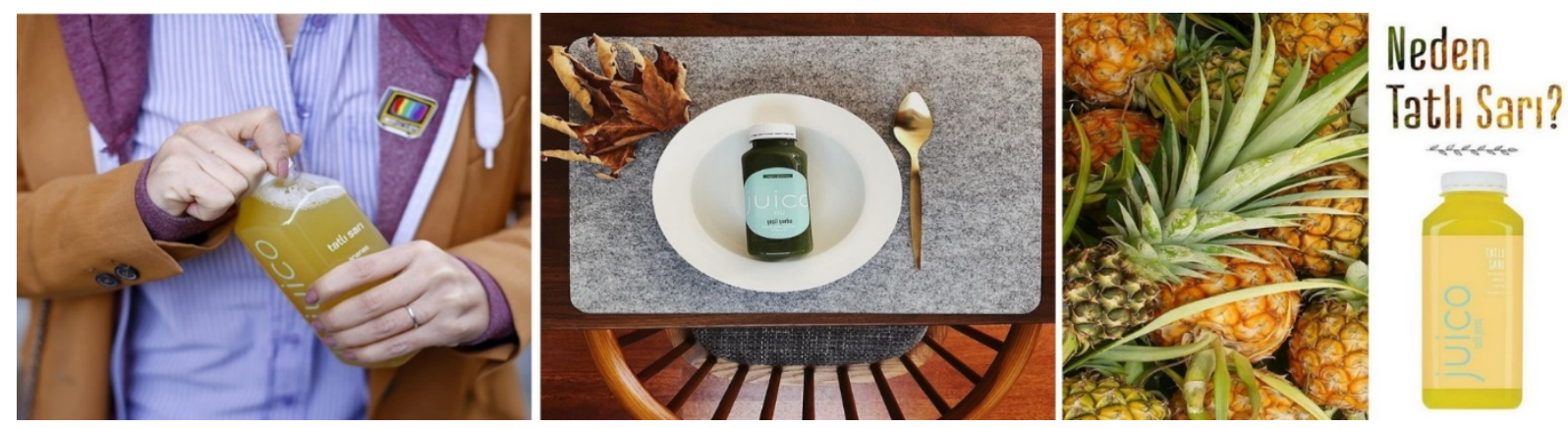

\section{Herby Tea}

Herby Tea markası, günlük hayatta karşılaşılan sorunlara çözüm üreten ürün adlandırma ve sunumları, zaman ve gündem ile ürün ilişkilendiren paylaşımlara yer vermesi dolayısı ile 'samimi' ve 'heyecanlı' marka kişilik özellikleri sergilemektedir.

\section{Görsel 4: Herby Tea Marka Kişiliği Paylaşım Örnekleri}
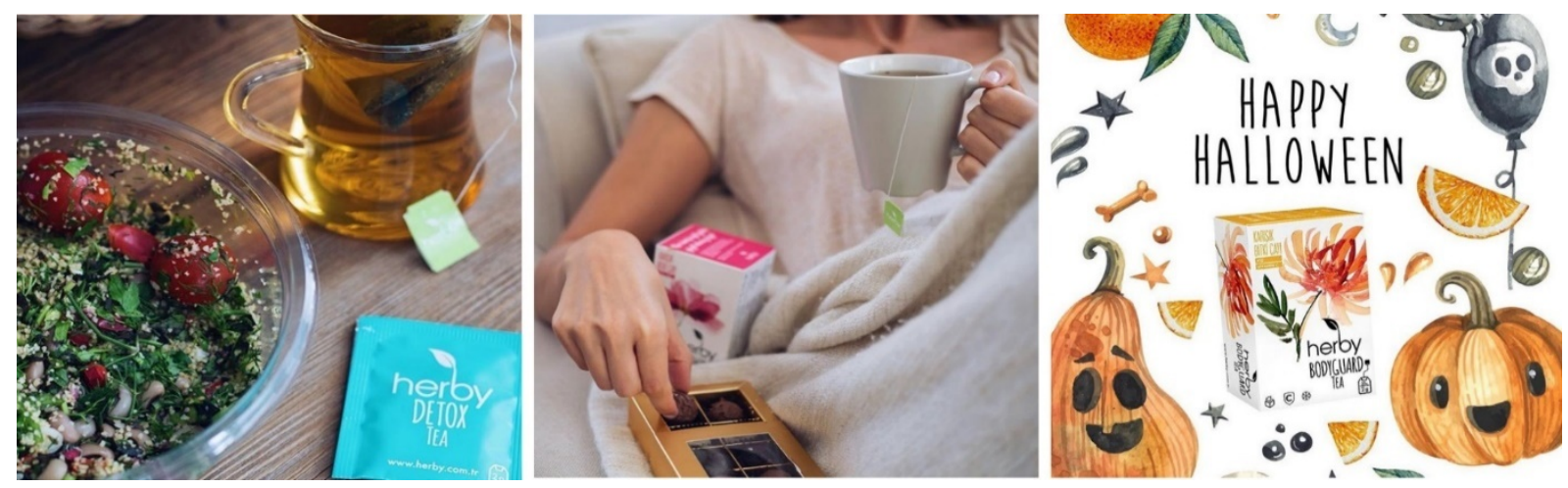

\section{Mahmood Coffee}

Mahmood Coffee markası, güncel olayları takip eden, neşeli, gündelik hayat ve eğlence temalı söylemler ile birlikte oyun temalı paylaşımlara ağırlık vermesiyle 'samimi' marka kişiliği özellikleri sergilemektedir.

Görsel 5: Mahmood Coffee Marka Kişiliği Paylaşım Örnekleri
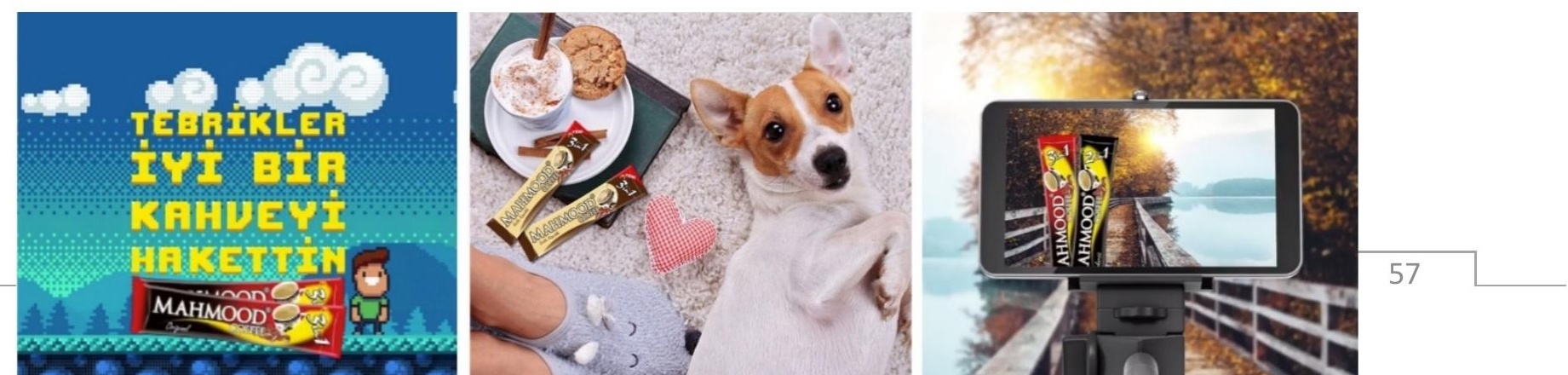


\section{SONUÇ}

Marka iletişimi açısından pazarlama ve iletişim taktiği olarak Instagram'da paylaşılan görsellerin özellikleri ve betimledikleri marka kişilik unsurlarını içecek markaları üzerinden ortaya çıkarmayı amaçlayan çalışmada, araştırmanın örneklemi Social Brands'in 2018 yılı Ekim ayı Sosyal Medya Araştırması'na göre, Instagram'daki En Başarılı İçecek Markaları sıralamasında yer alan ilk 5 marka (Red Bull Türkiye, Dimes Türkiye, Juico, Herby Tea ve Mahmood Coffee) ile sinırlandırılmıştır.

Ginsberg (2015) ve Aeker (1997)'ın çalışmalarından yararlanılarak katılımcı gözlem ve içerik analizi yöntemlerinin kullanıldığı çalışmada elde edilen veriler sonucunda; analiz kapsamına alınan içecek markalarının pazarlama ve iletişim taktiği olarak Instagram'da kullandıkları görsellerin daha çok ürün tanıtımı, yaşam tarzı ve marka-ürünle ilgili etkinlik/deneyim içerdiği tespit edilmiştir. Dolayısıyla markaların sadece kendi ürünleriyle ilgili görseller paylaşmadığı, sosyal ve kültürel içerikli görseller de paylaştığı, böylece görsellerin ürünlerin ötesine geçerek tüketicilerle etkileşim ve bağlantı kurduğu söylenebilmektedir.

Markalar tarafından paylaşılan görsellerin sergiledikleri marka kişilik boyutlarına bakıldığında, markaların daha çok samimi, heyecanlı, sağlam ve yetkin marka kişiliği gösterdikleri tespit edilmiş olup, markaların Aaker'in marka kişiliğinin beş boyutunun neredeyse tamamına ait özellikler içeren paylaşımlarda bulunduğu görülmüştür. Özellikle marka konumlandırma konusunda yoğun emek harcayan markaların (Red Bull Türkiye, Juico, Herby Tea) birden çok marka kişilik özelliği sergiledikleri, diğer markaların (Dimes Türkiye, Mahmood Coffee) ise ağırlıklı olarak tek bir marka kişilik özelliği sergiledikleri tespit edilmiştir.

Markaların kişilik yaratma motivasyonları, çalışmanın kapsamı dışında bırakılmasından dolayı ölçümlenmemiş olmakla birlikte, bir sonraki aşamada, markaların kişilik yaratma plan ve motivasyonları ile takipçiler tarafından bu kişilik sunumlarının ne şekilde alımlandığına yönelik çalışmaların bu çalışmayı tamamlayıcı nitelikte olacağı öngörülmektedir. Çok yönlü ve uzun vadeli uğraşı gerektiren marka kişiliği yaratma faaliyetleri bu çalışmada markaların sunumları üzerinden tek yönlü olarak ölçümlenmekle birlikte, markaların paylaşım içeriklerindeki zenginliğin ve marka kişiliklerinin çok boyutlu olmasının, markaların gerçek dünyadaki faaliyetleri ve hedef kitle etkileşimleriyle doğru orantılı olduğu ve duygusal etkileşim amacının ön planda tutulduğu sonucuna ulaşılmıştır.

\section{KAYNAKÇA}


Aaker, J. L. (1997). Dimensions of brand personality. Journal of Marketing Research, 34(3), 347-355. Retrieved from http://www.haas.berkeley.edu/groups/finance/ Papers/Dimensions\%20of\%20BP\%20JMR\%201997.pdf (November 17, 2018)

Alyanak, B. A. (2014). Etnografi ve Çevrimiçi Etnografi. In Mutlu Binark (Ed.), Yeni Medya Çalışmalarında Araştırma Yöntem ve Teknikleri (pp. 117-164). İstanbul: Ayrıntı Yayınları.

Bui, T. (2014). Social Media on a Stick: A uses and gratification approach toward helping mobile food vendors engage consumers on Instagram. Unpublished master's thesis, The University of Minnesota.

Dölarslan, E. Ş. (2012). Bir Marka Kişiliği Ölçeği Değerlendirmesi. Ankara Üniversitesi SBF Dergisi, 67(2), 1-28.

Geray, H. (2004). Toplumsal Araştırmalarda Nicel Ve Nitel Yöntemlere Giriş. Ankara: Siyasal Kitabevi.

Ginsberg, K. (2015). Instabranding: Shaping the Personalities of the Top Food Brands on Instagram. The Elon Journal of Undergraduate Research in Communications, 6(1), 7895

Goldberg, R. L. (1993), The Structure of Phenotypic Personality Traits. American Psychologist, 48 (1), 26-34.

Kale, G.Ö. (2016). Marka İletişiminde Instagram Kullanımı. The Turkish Online Journal of Design, Art and Communication (TOJDAC) 6(2), 119-127.

Meer, L., (2010). Communicating Destination Brand Personality: The Case of Amsterdam, Unpublished master's thesis, University of Applied Sciences. Retrieved from http://www.tourism-master.com/wp-content/uploads/2011/03/Thesis_Communica ting-destination-brand-personality_Laura-van-Meer_2010.pdf (November 21, 2018).

Milas, G. \& Mlacic, B. (2007), Brand Personality and Human Personality: Findings from Ratings of Familiar Croatian Brands. Journal of Business Research, 60, 620-626.

Plummer, J., T. (2000). How Personality Makes a Difference. Journal of Advertising Research, $40(6), 79-84$.

Sweeney, C. J. \& Brandon, C. (2006). Brand Personality: Exploring the Potential to Move from Factor Analytical to Circumplex Models. Psychology \& Marketing, 23 (8), 639-663.

Ting , H., Ming, W. W. P., Run, E. C. \& Choo, S. L. Y. (2015). Beliefs about the Use of Instagram: An Exploratory Study. International Journal of Business and Innovation. 2(2), 15-31.

Torlak, Ö. \& Özçelik, D. G., (2011). Marka Kişiliği Algısı İle Etnosentrik Eğilimler Arasındaki İlişki: Levis ve Mavi Jeans Üzerine Bir Araştırma. Ege Akademik Bakış, 11(3), 361- 377

Yakın, V. \& Ay, C. (2012). Markaların Kişilik Arketiplerinin Algılanması Üzerine Bir Çalışma. The Turkish Online Journal of Design, Art and Communication (TOJDAC), 2(3), 27-36.

Yıldırım, A. \& Şimşek, H. (2006). Sosyal Bilimlerde Nitel Araştırma Yöntemleri. Ankara: Seçkin Yayınları.

Yılmaz, M., (2007), Marka Kişiliğinin Boyutları ve İkea Uygulaması, Unpublished master's thesis, Yıldız Teknik Üniversitesi Sosyal Bilimler Enstitüsü. 
AJIT-e: Online Academic Journal of Information Technology

2018- Informatics and Communication Technologies Special Issue/iletişim ve Bilişim Teknolojileri

Özel Sayı -Cilt/Vol: 9-Sayı/Num: 35

DOI: 10.5824/1309-1581.2018.5.004.x

Yücel, Nurcan \& Halifeoğlu, M. (2017). Marka Kişiliği Algısı: Sosyal Medya Markaları Üzerine Üniversite Öğrencilerine Yönelik Bir Araştırma. Fırat Üniversitesi Sosyal

Bilimler Dergisi -The Journal of International Social Sciences, 27(2), 177-191

\section{Ek-1: Görsel İleti Temaları/Kodlama Tablosu}

\begin{tabular}{|c|c|c|c|c|c|}
\hline \multicolumn{2}{|r|}{ Görsel İleti Temaları } & Örnek İçerik & \multicolumn{2}{|r|}{ Görsel İleti Temaları } & \multirow[t]{2}{*}{ Örnek İçerik } \\
\hline 1 & Ürün & & 8 & $\begin{array}{l}\text { Marka ve ürünü içeren } \\
\text { kampanya desteği }\end{array}$ & \\
\hline 2 & Ürün kampanya & & 9 & $\begin{array}{l}\text { Marka bağlantısız } \\
\text { deneyim/olay }\end{array}$ & \\
\hline 3 & Kişi/kişiler ve Ürün & & 10 & Kutlama/Anma & \\
\hline 4 & $\begin{array}{l}\text { Mizah/Eğlence ve } \\
\text { Ürün }\end{array}$ & 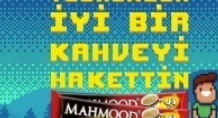 & 11 & $\begin{array}{l}\text { Tarifler/Ürün } \\
\text { kullanımları }\end{array}$ & \\
\hline 5 & $\begin{array}{l}\text { Marka } \\
\text { BağlantılıOrganizasyon }\end{array}$ & & 12 & $\begin{array}{l}\text { Yaşam Biçimi -ürünü } \\
\text { destekleyen içerik }\end{array}$ & \\
\hline 6 & $\begin{array}{l}\text { Marka /ürün içeren } \\
\text { Etkinlik/ deneyim }\end{array}$ & & 13 & $\begin{array}{l}\text { Yaşam Biçimi - bir } \\
\text { ürünü desteklemeyen } \\
\text { ancak marka ile } \\
\text { bağlantılı içerik }\end{array}$ & \\
\hline
\end{tabular}


Marka Kişiliklerinin Instagram Aracılığıyla Sunumu: Iç̧ecek Markaları Üzerine Analiz H. KÜÇÜKSARAÇ

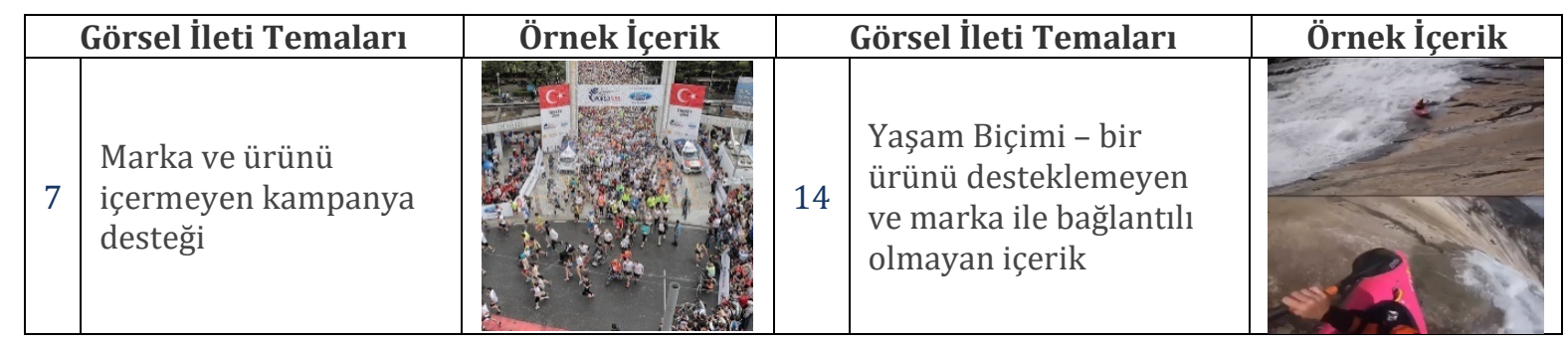

